\title{
Research Paper: Time Use of Mothers of Children With an Autism Spectrum Disorder: A Comparative Study
}

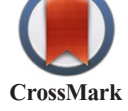

Fatemeh Behnia', Mehdi Rassafiani ${ }^{2}$, Sara Nakhai ${ }^{3}$, Maryam Mohammadpour ${ }^{1}$, Mina Ahmadi Kahjoogh ${ }^{\text {* }}$

1. Department of Occupational Therapy, University of Social Welfare and Rehabilitation Sciences, Tehran, Iran.

2. Pediatric Neurorehabilitation Research Centre, University of Social Welfare and Rehabilitation Sciences, Tehran, Iran.

3. Claudio Santi Social Medicine Center, Rehabilitation Unit, Don Calabria Institute, Verona, Italy.

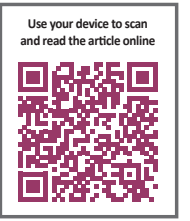

Crtation: Behnia F, Rassafiani M, Nakhai S, Mohammadpour M, Ahmadi Kahjoogh M. Time Use of Mothers of Children With an Autism Spectrum Disorder: A Comparative Study. Iranian Rehabilitation Journal. 2017; 15(1):49-56. https://doi. org/10.18869/nrip.irj.15.1.49

https://doi.org/10.18869/nrip.irj.15.1.49

Article info:

Received: 14 Oct. 2016

Accepted: 12 Dec. 2016

\section{Keywords:}

Autism spectrum disorder, Disability, Mothers' time use, Occupational balance, Participation

\section{A B S T RACT}

Objectives: Studies around the world have shown that having a child with disability impacts a mother's time use. The purpose of this study was to compare the time use of mothers of children with Autism Spectrum Disorder (ASD) with mothers of typically developing children.

Methods: Eighty-four Iranian mothers ( 42 with ASD children and 42 with typically developing children) completed the Mothers' Time Use Questionnaire (MTUQ).

Results: Mothers of ASD children spent more time doing childcare activities $(\mathrm{P}<0.001)$, but no significant differences were found in time spent in self-care, rest/sleep, leisure, household chores, job or social participation activities. Furthermore, quality and enjoyment of daily activities were significantly lower in mothers of children with ASD compared to mothers of typically developing children.

Discussion: Mothers of ASD children are more prone to having an imbalanced life. Hence, there is a need for occupational therapists to work in partnership with mothers to support their occupational engagement and life satisfaction.

\section{Introduction}

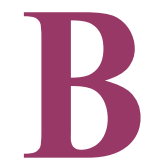

alance between different areas of occupation including self-care, rest/sleep, productivity, and leisure is considered important in occupational therapy models [1]. The balance can be achieved when a person has organized daily routines [2] and balance is needed to have satisfaction and appropriate decisionmaking power [3]. Knowledge of time use patterns of people can be a good way to help them promote their health and quality of life [4]. Time use studies are usually conducted by governmental organizations or health professionals to make decisions for the society and have knowledge about how persons use their time during a day. Occupational therapists usually consider the concept of temporal adaptation. When people get adapted to their life demands in relation to use of time, it means that temporal adaptation has been achieved [5]. Sometimes people encounter challenges in their life that can

\section{* Corresponding Author:}

Mina Ahmadi Kahjoogh, PhD

Address: Department of Occupational Therapy, University of Social Welfare and Rehabilitation Sciences, Daneshjoo Blv., Velenjak, Tehran, Iran. Tel: +98 (21) 22180037

E-mail: mina_ot5520@yahoo.com 
affect their time use. Mothers of children with disability are more likely to lose balance in their daily life. Awareness of time use identifies the impact of having a disabled child on mother's time use $[3,6]$.

Studies have shown that time use of persons with disability and their caregivers are different from other people without disability [7-9]. Crowe and Florez (2011) stated that mothers of adolescents with disabilities allocate considerably more time to supervise their children compared to mothers who have children without disability. In other words, the disability factor plays a major role in preventing these mothers from participating in other meaningful occupations, resulting in them experiencing more stress and time pressure [10-12]. Most of the time, the mothers take the responsibility of taking care of their children. When the child is born with a disability, $\mathrm{s} /$ he needs more supports in terms of medical and rehabilitation interventions $[13,14]$.

Autism Spectrum Disorder (ASD) is one of most common psychiatric disorders with a prevalence of 1 in 110 [15]. In Iran, the prevalence of ASD is estimated to be $1.9 \%$ in school-aged children [16]. Mothers of children with disability take more time to look after their children; therefore, they spend less time in entertainment and enjoyable activities $[17,18]$. Van Leit and Crowe found that spending deserving time for different areas of occupations has a proper effect on satisfaction with occupational performance of mothers of children with disabilities [19].

The kind of disability and its severity, cultural values and the age of child are the important factors that determine how the mothers cope with the situation $[3,20$, 21]. Accessible resources have an important impact on time use of mothers of children with disabilities [22]. Problems in communication and emotional expression also put tremendous pressure on such mothers. Parents of a child with ASD report poorer well-being in comparison to parents having children with other kinds of disabilities, such as cerebral palsy and Down syndrome $[23,24]$.

The purpose of this study was to compare the time use of mothers of children with ASD and mothers of typically developing children. The two research questions were: 1) What is the difference in the time use of mothers of children with ASD in comparison to mothers of typically developing children?; and 2) What is the difference in the quality of time use of mothers of children with ASD and mothers of typically developing children?

\section{Methods}

\section{Participants}

A cross-sectional survey with a matched control group was used for this study. A convenient sampling method was employed to select the participants. The study population consisted of 42 mothers of children with ASD (ASD group) and 42 mothers of typically developing children (typically developing (TD) group). The mean age for the children with ASD was 6.4 years $\left(\mathrm{SD}^{1}=1.8\right)$ and 6.5 years $(\mathrm{SD}=2.3)$ for typically developing children. There were no significant differences between group ages (Table 1).

Inclusion criteria for all mothers were having a maximum of three children with at least one child between 3 to 11 years old, being over 25 years old, not being responsible for caring for any other person with disabilities such as a parent, not having a child under the age of one year, living with husband, being literate, and consenting to participate in the study (Table 2). The mothers in the TD group did not have any children with disabilities. The mothers in the ASD group had a child with ASD but no other children with disabilities. The children with ASD were qualified by the Gilliam autism rating scale (GARSII) [25]. This questionnaire assessed the probability of ASD and its severity. An experienced occupational therapy (OT) master did the test. Thirty-one participants were with medium probability and 11 with a high probability of having ASD. If a child with ASD had a visual or hearing impairment, seizures, an orthopedic condition, or another disability, the mother was excluded from the study.

\section{Instruments}

The instruments were an authored designed demographic questionnaire, GARS-II [25], and the Mother's Time Use Questionnaire (MTUQ) [3]. The demographic questionnaire surveyed the demographic characteristics of the mother, child and family.

The GARS-II was designed to assess the probability of ASD and its severity and can be administered to people from ages 3 to 22 years. The scale consists of three subscales: stereotyped behaviors, communication, and social interaction. Each subscale contains 14 items, and the frequency of each behavior is rated on a 4-point scale: (a) never observed, (b) seldom observed, (c) sometimes observed, and (d) frequently observed. The scores of the three subscales were added together and converted to standard scores to determine the severity of ASD. Scores 1. Standard Deviation 
of 52 or below indicated a low probability of ASD, 53 to 84 medium probability and over 85 high probability of having ASD. The scale was validated for Iranian children from 3 to 18 years, and the internal consistency reliability (Cronbach's alpha coefficient) was found to be 0.89 [20].

The MTUQ (3) was used to collect data on mothers' time use patterns. The MTUQ consists of four sections (Quality of mother's time management skills, Leisure, General questions of time management, and a Time log table). Only the time log table has been reported in this study. According to the developers, using sections of the MTUQ separately was acceptable. Activities in the time use section were classified by the mother into seven areas: self-care, rest/ sleep, childcare, leisure, household chores, work/job, and social participation. The mothers were asked to record their activities on a typical day from 5 in the morning to 12 (midnight) with 1-hour intervals. The MTUQ also asked about the importance of occupations (not reported), the quality of doing occupations, and the enjoyment derived from occupations using a Likert scale. For example, quality of doing occupations was rated as follows: 1) very well, 2) well, 3 ) average, 4) poorly, and 5) very poorly. The MTUQ was translated through several phases according to the guidelines provided by the WHO [26].

These steps were as follows: (1) two people with an acceptable command on both Farsi and English translated the MTUQ separately to provide two Farsi versions; (2) the two versions were discussed by a team of translators and researchers to solve the disputed terms and reach one single version; (3) the Farsi version was sent to two other people to be translated back into English; (4) a team of translators and researchers reached a single translation following a meeting; (5) the English version was sent to the developers of the MTUQ for their approval; and (6) the developers' comments and suggestions were integrated into a final MTUQ version. The test-retest reliability coefficient was calculated to be between 0.78 to 0.89 in a previous study conducted in Iran $[3,7]$.

\section{Procedures}

This study was approved by the Ethical Committee of the University of Social Welfare and Rehabilitation Sciences, Tehran, Iran. Ethical considerations included informing the parents about possible benefits of participating in this research, signing an informed consent form, maintaining confidentiality of the disclosed information, and not imposing any financial costs on families.
The researchers visited the Autism Training and Rehabilitation Day Centers to recruit participants. Mothers of children with ASD (3 to 11 years) were invited to participate in the study. The mothers then received clarification on the objectives of the study and once they fully agreed to participate in the study, the researchers gave them consent forms to read and sign. The study questionnaires were then distributed. The mothers were encouraged to ask questions in order to complete the questionnaires accurately.

The mothers of typically developing children were selected from the elementary schools and kindergartens close to the special schools and clinics in the same district. Students were given the questionnaires to take home and give it to their mothers. Along with this questionnaire, there were a letter of consent and the demographic questionnaire. The next week, the questionnaires and consent forms that were completed by the mothers were collected. After reviewing the questionnaires, the mothers who matched mothers of children with ASD were included in the study.

\section{Statistical analysis}

Standard descriptive statistics (means and SD) were computed for the ages of mothers and children, educational levels of the mothers, number of children, and employment status. Independent t-tests and $\mathrm{x}^{2}$ test were used to examine the differences between the two groups of mothers. Independent t-tests were used for age, number of children, time use, quality of doing work and enjoyment, and $\mathrm{x}^{2}$ test was used for level of education and employment status. A P-value of lower than 0.05 was considered to be statistically significant. Data were analyzed using Statistical Package for Social Sciences (version 17).

\section{Results}

Findings of this study are divided into two sections. The first section describes the demographic characteristics in both the groups; the second part analyzes the data pertaining to differences in time use patterns and quality aspects of time use between mothers in the groups.

The mothers were matched in both groups in terms of their child's age, number of children and employment status, with a probability higher than 0.05 (Tables 1 and 2). Table 3 shows the time use patterns in mothers of ASD children and those with typically developing ones. Mothers of children with ASD spent significantly more amount of time during the day on caring for their children. Quality of doing occupations and the enjoyment driven with them 
Table 1. Distribution of age in mothers and their children in two groups

\begin{tabular}{ccccc}
\hline & \multicolumn{2}{c}{ Children } & \multicolumn{2}{c}{ Mothers } \\
\cline { 2 - 5 } & $\begin{array}{c}\text { Typically Developing Chil- } \\
\text { dren }\end{array}$ & Children With ASD & With Typically Developing Children & $\begin{array}{c}\text { With Children With } \\
\text { ASD }\end{array}$ \\
\hline $\begin{array}{c}\text { (Age) } \\
\text { Mean }\end{array}$ & 6.41 & 6.49 & 35.07 & 33.09 \\
SD & 1.81 & 2.32 & 5.3 & 4.3 \\
\hline P & & 0.78 & & 0.06 \\
\hline
\end{tabular}

Iranian Rehabilitation Đourna

were significantly less in mothers of children with ASD in comparison to the mothers of the other group (Table 4).

\section{Discussion}

Occupational balance is an important concept in occupational therapy. It is a challenging matter but again a serious affair in promoting health. If it has been defined as a balance between daily activities and balance among activities, it can improve health and welfare [28, 29]. Occupational balance is an individual issue, and it talks of the way by which an individual can align their daily activities in order and earmark a specific amount of time for self-care, productivity and leisure times with satisfaction $[11,29,30]$. Mothers of children with disability try to create a balance between their family matters, work and leisure activities, although they are usually forced to engage in child-related activities $[6,7,14]$.
The contextual factors would play an important role in taking out time for different domains of activities [31] According to the findings, mothers of children with ASD significantly spend more time to care for their children in comparison to the mothers who had typically developing children. Although there was no statistically significant differences between other areas of occupation between the two groups, the mothers of children with ASD allocated less time to self-care activities, rest/sleep, paid works and social participation. These results indicated a sign of imbalance in spending time for meaningful occupations in mothers of children with ASD. Spending more time for tasks related to the taking care of a child with ASD by the participants of this study was similar to the results of similar studies, which had been conducted to examine various impacts on the mother's time use who have children with disability [3, 6, 7, 14, 18, 27].

Breslau showed no difference between two groups of participants in taking care of children although. In this study,

Table 2. Analysis of the level of education, the number of children and the employment status of mothers in the two groups

\begin{tabular}{|c|c|c|c|c|c|c|}
\hline \multirow{2}{*}{\multicolumn{2}{|c|}{ Variables }} & \multicolumn{2}{|c|}{$\begin{array}{c}\text { Mothers of Typically Devel- } \\
\text { oping Children }\end{array}$} & \multicolumn{2}{|c|}{ Mothers of Children With ASD } & \multirow{2}{*}{$\mathbf{P}$} \\
\hline & & Number & Percentage & Number & Percentage & \\
\hline \multirow{3}{*}{ Educational level } & Below high school diploma & 5 & 11.9 & 7 & 16.7 & \multirow{3}{*}{0.71} \\
\hline & High school diploma & 14 & 33.3 & 11 & 26.2 & \\
\hline & University degree & 23 & 54.8 & 24 & 57.2 & \\
\hline \multirow{3}{*}{ Number of children } & 1 & 15 & 35.7 & 19 & 45.2 & \multirow{3}{*}{0.29} \\
\hline & 2 & 18 & 49.2 & 19 & 45.2 & \\
\hline & 3 & 9 & 21.4 & 4 & 9.5 & \\
\hline \multirow{3}{*}{ Occupational status } & Working & 17 & 40.5 & 11 & 26.2 & \multirow{3}{*}{0.16} \\
\hline & & & & & & \\
\hline & Not working & 25 & 59.5 & 31 & 73.8 & \\
\hline
\end{tabular}


Table 3. Comparison between the two groups in terms of time spent in each occupational are in hours for 14 hour day

\begin{tabular}{|c|c|c|c|}
\hline Variables & Groups & Mean(SD) & $\mathbf{P}$ \\
\hline Self-care & $\begin{array}{c}\text { Mothers of TD children } \\
\text { Mothers of children with ASD }\end{array}$ & $\begin{array}{l}2.16(0.82) \\
2.02(0.81)\end{array}$ & 0.42 \\
\hline Rest/sleep & $\begin{array}{l}\text { Mothers of TD children } \\
\text { Mothers of children with ASD }\end{array}$ & $\begin{array}{l}4.33(1.63) \\
4.26(1.65)\end{array}$ & 0.84 \\
\hline Childcare & $\begin{array}{l}\text { Mothers of TD children } \\
\text { Mothers of children with ASD }\end{array}$ & $\begin{array}{l}2.92(1.4) \\
4.26(1.86)\end{array}$ & $<0.001^{*}$ \\
\hline Leisure time & $\begin{array}{l}\text { Mothers of TD children } \\
\text { Mothers of children with ASD }\end{array}$ & $\begin{array}{l}2.28(1.25) \\
2.4(1.38)\end{array}$ & 0.68 \\
\hline Household chores & $\begin{array}{l}\text { Mothers of TD children } \\
\text { Mothers of children with ASD }\end{array}$ & $\begin{array}{l}4.19(1.62) \\
4.19(1.54)\end{array}$ & 0.7 \\
\hline Work/ job & $\begin{array}{l}\text { Mothers of TD children } \\
\text { Mothers of children with ASD }\end{array}$ & $\begin{array}{l}2.64(3.58) \\
1.45(2.73)\end{array}$ & 0.09 \\
\hline Social participation & $\begin{array}{c}\text { Mothers of TD children } \\
\text { Mothers of children with ASD }\end{array}$ & $\begin{array}{l}0.45(0.7) \\
0.4(0.79)\end{array}$ & 0.77 \\
\hline
\end{tabular}

Iranian Rehabilitation Journal

taking care of a child with a disability was considered different from other child-related activities such as spending time to visit experts. In this particular study, mothers of children with disabilities spent six times more time visiting health professionals than mothers of typically developing children [12]. Previous studies have reported no difference in taking time in the areas of rest/sleep and self-care activities between mothers of children with different disabilities such as physical dysfunction, mental retardation, attention disorder and hyperactivity and cerebral palsy and mothers of children with no disabilities [3, 7, 18].

The results of this study recognized that mothers of children with ASD spent a little more time for leisure activities. One reason for this finding was engaging in passive recreational activities like accompanying the children with ASD in watching TV. There were no significant difference between the two groups related to household chores, paid work and social participation. This was similar to the findings by Gevir et al. (2006), Crowe et al. (2006) and Rassafiani et al. (2012) [3, 7, 14]. However, Crowe et al. (2011) stated that mothers of children with disabilities spent significantly less time in social activities than mothers who have typically developing children [6]. In addition, the age of children with disability might also be an important factor in mother's social participation. In quality aspects of time use, the results obtained from this study are different from those

Table 4. Comparison between the two groups in terms of enjoyment and quality of doing of occupations

\begin{tabular}{|c|c|c|c|}
\hline Variables & Groups & Mean(SD) & $\mathbf{P}$ \\
\hline \multirow{3}{*}{ Quality of doing } & Mothers of typically developing children & $80.07(6.65)$ & \multirow{3}{*}{$0.006^{*}$} \\
\hline & & & \\
\hline & Mothers of children with ASD & $75.78(7.19)$ & \\
\hline \multirow{3}{*}{ Enjoyment } & Mothers of typically developing children & $77.21(8.22)$ & \multirow{3}{*}{$0.03^{*}$} \\
\hline & & & \\
\hline & Mothers of children with ASD & $73.14(8.89)$ & \\
\hline
\end{tabular}

* There is a significant difference between the two groups in both quality aspects of time use.

Iranian Rehabilitation Journa 
obtained by previous studies $[3,7]$. The mothers of children with ASD had a lower quality of doing activities and the enjoyment compared to mothers having children without disability. While in other studies on mothers with children having cerebral palsy and mental retardation, no difference in enjoyment and quality of doing things was reported. This difference may be due to the type of disorder.

\section{Conclusion}

The results indicated that having a child with ASD can be a challenge for mothers to have a balanced time use. The mothers try to look after their children with ASD as good as they can. Due to this, they usually ignore their own needs and do occupations with lower enjoyment and poorer quality in comparison to mothers who have children without disabilities. With an understanding of how mothers spend their time, occupational therapists instruct mothers in the consultation part of their interventions on properly allocating their time with regard to their conditions of life so that their mental health may increase with decreasing stress level.

Limitations and Recommendations: Some variables would have an impact on time use that has not been considered, for example, gender of the child, financial status of the family and help of others at home. Having no special screening for typically developing children is another limitation of the study. It is important to examine time use of mothers with children with disabilities in different countries around the world to examine the cultural influences of time use. Comparison studies focused on time use need to be conducted in other countries.

\section{Acknowledgements}

This research did not receive any specific grant from funding agencies in the public, commercial, or not-forprofit sectors. We would like to give our special thanks to children and their parents who made this research possible. We are grateful to Professor Terry K. Crowe from the University of New Mexico for her kind help.

\section{Conflict of Interest}

The authors declared no conflicts of interest.

\section{References}

[1] Bejerholm U, Eklund M. Time use and occupational performance among persons with schizophrenia. Occupational Therapy in Mental Health. 2004; 20(1):27-47. doi: 10.1300/ j004v20n01_02

[2] Leufstadius C, Erlandsson LK, Eklund M. Time use and daily activities in people with persistent mental illness. Occupational Therapy International. 2006; 13(3):123-41. doi: 10.1002/oti.207

[3] Gevir D, Goldstand S, Weintraub N, Parush S. A comparison of time use between mothers of children with and without disabilities. Occupation, Participation and Health. 2006; 26(3):117-27. doi: 10.1177/153944920602600305

[4] Law M. The environment: A focus for occupational therapy. Canadian Journal of Occupational Therapy. 1991; 58(4):171-9. doi: $10.1177 / 000841749105800404$

[5] Kielhofner G. Temporal adaptation: A conceptual frame work for occupational therapy. American Journal of Occupational Therapy. 1997; 31(4):235-42. PMID: 848558

[6] Crowe T, Michael HO. Time use of mothers with adolescents: A lasting impact of a child's disability. Occupation Participation and Health. 2011; 31(3):118-26. doi: 10.3928/1539449220100722-01

[7] Rassafiani M, Kahjoogh MA, Hosseini A, Sahaf R. Time use in mothers of children with cerebral palsy: A comparison study. Hong Kong Journal of Occupational Therapy. 2012; 22(2):70-4. doi: 10.1016/j.hkjot.2012.11.001

[8] Crowe T, VanLeit B, Berghmans K, Mann P. Role perceptions of mothers with young children: The impact of a child's disability. American Journal of Occupational Therapy. 1997; 51(8):651-61. doi: 10.5014/ajot.51.8.651

[9] Awyer Mg, Bittman M, La Greca Am, Crettenden Ad, Borojevic N, Raghavendra P, et al. Time demands of caring for children with cerebral palsy: What are the implications for maternal mental health? Developmental Medicine \& Child Neurology. 2011; 53(4):338-43. doi: 10.1111/j.14698749.2010.03848.x

[10] Donovan JM, VanLeit BJ, Crowe TK, Keefe EB. Occupational goals of mothers of children with disabilities: Influence of temporal, social, and emotional contexts. American Journal of Occupational Therapy. 2005; 59(3):249-61. doi: 10.5014/ ajot.59.3.249

[11] Helitzer DL, Cunningham-Sabo LD, VanLeit B, Crowe TK. Perceived changes in self-image and coping strategies of mothers of children with disabilities. Occupation, Participation and Health. 2002; 22(1):25-33. doi: 10.1177/153944920202200104

[12] Breslau N. Care of disabled children and women's Time Use. Medical Care. 1983; 21(6):620-9. doi: 10.1097/00005650198306000-00004

[13] Razavi Afzal Z, Rassafiani M, Sarfaraz Z, Malekpour M, Salehi M. A survey on caregivers' knowledge about special caring for 1-to-5 year-old children with cerebral palsy and their compliance with these practices. Journal of Research in Rehabilitation Sciences. 2013; 9(4):618-628.

[14] Crowe T, Florez S. Time use of mothers with school-age children: A continuing impact of a child's disability. Ameri- 
can Journal of Occupational Therapy. 2006; 60(2):194-203. doi: 10.5014/ajot.60.2.194

[15] Koegel L, Matos-Freden R, Lang R, Koegel R. Interventions for children with autism spectrum disorders in inclusive school settings. Cognitive and Behavioral Practice. 2012; 19(3):401-12. doi: 10.1016/j.cbpra.2010.11.003

[16] Ghanizadeh A. A preliminary study on screening prevalence of pervasive developmental disorder in schoolchildren in Iran. Journal of Autism and Developmental Disorders. 2007; 38(4):759-63. doi: 10.1007/s10803-007-0445-6

[17] Werner DeGrace B. The everyday occupation of families with children with autism. American Journal of Occupational Therapy. 2004; 58(5):543-50. doi: 10.5014/ajot.58.5.543

[18] Smith LE, Hong J, Seltzer MM, Greenberg JS, Almeida DM, Bishop SL. Daily experiences among mothers of adolescents and adults with autism spectrum disorder. Journal of Autism and Developmental Disorders. 2009; 40(2):167-78. doi: 10.1007/s10803-009-0844-y

[19] VanLeit B, Crowe TK. Outcomes of an occupational therapy program for mothers of children with disabilities: Impact on satisfaction with time use and occupational performance. American Journal of Occupational Therapy. 2002; 56(4):40210. doi: 10.5014 /ajot.56.4.402

[20] Ahmadi S, Safari T, Hemmatian M, Khalili Z. [The psychometric properties of Gilliam Autism Rating Scale (GARS) (Persian)]. Journal of Cognitive and Behavioral Sciences. 2011; 1(1):87-104.

[21] Ahmadi Kahjoogh M, Rassafiani M, Tahmasebi A, Ahmadi Kahjoogh H, Sahaf R. The relationship between gross motor function ability and time use in mothers of children with cerebral palsy. British Journal of Occupational Therapy. 2016; 79(3):172-7. doi: 10.1177/0308022615616974

[22] Segal R. Adaptive strategies of mothers with children with attention deficit hyperactivity disorder: Enfolding and unfolding occupations. American Journal of Occupational Therapy. 2000; 54(3):300-6. doi: 10.5014/ajot.54.3.300

[23] Glidden LM, Billings FJ, Jobe BM. Personality, coping style and well-being of parents rearing children with developmental disabilities. Journal of Intellectual Disability Research. 2006; 50(12):949-62. doi: 10.1111/j.1365-2788.2006.00929.x

[24] Gray DE. Coping over time: The parents of children with autism. Journal of Intellectual Disability Research. 2006; 50(12):970-6. doi: 10.1111/j.1365-2788.2006.00933.x

[25] Gilliam J. Gilliam Autism Rating Scale. Austin: Pearson; 1995.

[26] World Health Organization. Family of international classifications Network. Geneva: World Health Organization; 2004.

[27] Curran AL, Sharples PM, White C, Knapp M. Time costs of caring for children with severe disabilities compared with caring for children without disabilities. Developmental Medicine \& Child Neurology. 2007; 43(8):529-33. doi: 10.1111/ j.1469-8749.2001.tb00756.x.

[28] DeLany J, Jones M. Time Use of teen mothers. Occupation, Participation and Health. 2009; 29(4):175-82. doi: 10.3928/15394492-20090914-05
[29] Anaby DR, Backman CL, Jarus T. Measuring occupational balance: A theoretical exploration of two approaches. Canadian Journal of Occupational Therapy. 2010; 77(5):280-8. doi: 10.2182/cjot.2010.77.5.4

[30] Wilcock AA, Chelin M, Hall M, Hamley N, Morrison B, Scrivener $\mathrm{L}$, et al. The relationship between occupational balance and health: A pilot study. Occupational Therapy International. 1997; 4(1):17-30. doi: 10.1002/oti.45

[31] Yazdani F, Roberts D, Yazdani N, Rassafiani M. Occupational balance: A study of the sociocultural perspective of Iranian occupational therapists. Canadian Journal of Occupational Therapy. 2016; 83(1):53-62. doi: 10.1177/0008417415577973 
